\title{
On the Construction of Positive Psychology in Higher Vocational College Students' Mental Health Education
}

\author{
Ting Long ${ }^{* 1}$ \\ ${ }^{1}$ Yunnan Vocational College of Finance and Economics, Kunming, Yunnan Province, China \\ *Corresponding author. Email: llinnnd@gmail.com
}

\begin{abstract}
Higher vocational students' psychological education in the higher vocational students' learning career is very important to explore the application of positive psychology in the process of higher vocational education psychology, conduce to improving the quality of higher vocational student's psychological education and higher vocational student's psychological quality, understanding the connotation of positive psychology in this article, through reading literature, combined with the actual teaching experience, applying positive psychology to the higher vocational students psychological health education, provide a reference for practitioners and educators.
\end{abstract}

Keywords: Positive psychology, Vocational college students, Mental health

\section{INTRODUCTION}

Difference in the planning and development, clearly points out the development direction of the country's future and plan, education development has been one of countries focus on the project, in one hundred for education, mental health education in higher vocational school education is an important part of the party to set up the students learning and grasp the students' thought has important role in the dynamic. Li Canyang [1] research shows that the students in the process of facing the employment pressure, and school, it is easy to appear the psychological problems, this requires the teacher's guidance and timely guidance, help students to correct relieve psychological pressure, pressure is too big, can easily cause students disgusted with pessimistic mood, and even lead to students began to close self, don't want to communicate with others, to solve these problems, requires positive action; Shi Jing [2] pointed out that there are certain psychological differences between students through the research on the psychological state of higher vocational college students, and differentiated guidance is still needed according to the different states of students. Deng Bilin et al.[3] points out that there are many factors that can affect students' psychological condition, gender differences, family situation, etc are all will cause the reason for the state of students' psychological problems, take active measures of psychological education was very important, through the application of positive psychology, teachers can very good guides the student to set up the correct ideas, help students to complete the job, guide students to establish a good interpersonal relationship in the process of interpersonal communication, this paper expounds the current status quo of psychological education in higher vocational colleges, and put forward the application of positive psychology according to the status quo of the strategy.

\section{CURRENT STATUS OF MENTAL HEALTH EDUCATION IN HIGHER VOCATIONAL COLLEGES}

\subsection{The Target of Mental Health Education Is Not Clear}

At present, China's higher vocational education is one of the national key education, the development speed of higher vocational education has been improved, has entered a period of rapid development, the requirements for higher vocational educators are also improved. Compared with ordinary college students, the advantage of vocational college students is that they have special skills, and the purpose of vocational school is to train students with professional skills. Compared with ordinary universities, the disadvantage is that the level of cultural subjects is low, and the learning of cultural courses in vocational colleges is lack of scientific rationality [4]. Higher vocational students in planning their own career, social development puts forward higher requirements on 
higher vocational students, vocational students need to possess skills and become a high skill talented person, the conflict of higher vocational student's psychological health problem is more and more outstanding, most of the higher vocational students failed in the exam, lead to students in the choice of educational institutions, can only choose higher vocational education, to learn a skill, it also led to some vocational students feel inferior, anxious, cannot see their strengths and lack of confidence, lack of progress of hope, this is totally different from college students' psychological characteristics. Therefore, at present, the psychological goal of higher vocational health education is to solve most students' psychological problems and inferiority, anxiety, depression and other psychological problems. Application of positive psychology in the higher vocational education, need more starting from the psychological state of students, not only to correct the students' point of view, but also solve the students' inferiority complex emotions such as anxiety, guides the student positive upward, cannot use ambiguous attitude of psychological education to the teaching of higher vocational students, countries need high skilled talents more in the future, so pay attention to the psychological state of the students, set up the correct mental health education goal is very necessary.

\subsection{Mental Health Education Pays Attention to Solving Psychological Problems}

Traditional mainstream psychology, such as behaviorism, psychoanalysis and cognitive psychology, all aim at "people with psychological problems" , and this negative mental health education model ignores the positive power of the individual [5]. At present, the concept of mental health education in higher vocational colleges is largely based on the traditional mainstream psychology, and the educational work on psychological problems has been carried out. Mental health educators are like "firefighters," putting out fires wherever they are. This passive model of mental health education aims to solve problems, neglecting to explore the personal interests of high school students, stimulating the motivation for personal growth and finding meaning in life. In other words, there is a lack of mental health education concepts that can be prevented before problems arise.The number of students with mental illness mainly exists in higher vocational colleges is relatively small, and most vocational students have mental health. This needs to adjust the focus of mental health education, expand the scope of mental health education. Positive psychology holds that there are two mutually exclusive forces in each person's mind. There are positive forces, such as optimism, perseverance, gratitude, humor, courage, creativity, etc., and there are negative forces, such as depression, fear, anxiety. When negative forces are dominant, individuals will exhibit negative personality traits such as low self-esteem, anxiety and fear, while when positive forces are dominant, they will exhibit positive personality traits such as gratitude and kindness, teamwork, creativity and commitment to learning.Practice has proved that positive personality traits will affect people's healthy development. Positive personality traits should constantly enhance your inner positive forces and translate them into your personal life, study and work habits. In higher vocational mental health education, teachers are required to stimulate the positive power of students' diversified personalities, guide students to constantly enhance their own advantages, and apply the positive power to life, work and study.

\subsection{The Content of Mental Health Education Is Single}

In the tradition, mental health education simply solves students' psychological problems, while the course of mental health education means to carry out psychological investigation on freshmen, provide case consultation, impart mental health knowledge to students, intervene psychological problems, and create a positive campus cultural atmosphere. Setting scientific, reasonable and effective innovation mechanism, creating a positive campus cultural atmosphere, stimulating students' ability to discover, research and solve problems, continuing to cultivate learning, practice and practice skills, and caring for students' talent growth are the main purposes of designing psychological teaching courses in vocational colleges [6]. The mental health educators in higher vocational colleges must actively create conditions to effectively guide higher vocational students to actively participate in campus associations and social practices. Know your leisure interests, school interests, future career interests, etc. Stimulate curiosity, can learn more knowledge, and become an expert in a specific field, in order to achieve good results.

\section{THE APPLICATION OF POSITIVE PSYCHOLOGY IN THE PROCESS OF MENTAL HEALTH EDUCATION OF HIGHER VOCATIONAL COLLEGE STUDENTS}

Correctly guide students to establish healthy values, promote the students to explore the development of their own value, need to apply positive psychology education idea, starting from the concept level of students, correct guidance, stimulate students' interest in learning, help students set up healthy mental state, to promote students progress and from the potential, find their own strengths, the effect of the psychological education is the best, mainly elaborated the following the direction of the application of positive psychology. 


\subsection{Establish a Positive Concept of Education}

Generally, is psychology education for students and the teacher is serious, the influence of the traditional psychology education generally reflects the negative state of mind, after found the problem to solve the problem, it is in itself a negative performance, all of our traditional teaching methods of mental health in a certain extent, the application of negative psychology, affect the teachers and students in the process of accepting psychological state, therefore the need for larger change in order to eliminate these effects and positive psychology education effectively. The application of positive psychology first requires a conceptual change and must form the concept of healthy and progressive psychological education [7]. In the course of psychological education lectures, it is necessary to make use of the content of positivity to stimulate students' positive emotions. Generally speaking, the examples given by the teacher in the course of teaching should have a positive impression, and the cases selected should also be positive. In the course, it is necessary to arouse people's interest and further diversify the teaching content, so that students can form positive emotions and develop their enthusiasm. Finally, in the aspect of psychological counseling, psychological teachers must explore students' noble quality and individual potential, help students to establish self-confidence, guide students to form a positive idea, reduce the impact of negative psychology on students. Traditional psychology pays more attention to the change of moral education, the persuasion of students' psychological problems and the elimination of negative psychology. In fact, when a student has psychological problems, from the perspective of positive psychology, the student's positive psychology is not enough to help him form a healthy and upward concept. These traditional concepts of psychological education can hardly play a greater role in some students, and only by stimulating students' positive emotions can the problem be fundamentally solved.

\subsection{Construction of the Positive Education Model}

Education is different with the traditional psychology, the purpose of positive psychology is based on students' own, mainly through the guide, promote the students' potential excitation, in reference to the process of positive psychology, guides the student to set up the correct ideas, exert its maximum potential, but traditional psychology education is mainly to solve the problems about students' psychological, often after a student mental state problem, need to spend a lot of time for students psychological counseling, as a result, positive psychology concepts must be applied to all aspects of teaching, form the positive education mode, slowly accumulate to guide students. The positive psychology teaching mode can be divided into five stages. The first stage is mainly the observation of the students to understand the psychological state of the students displayed on the surface. Second, through continuous investigation of students, in-depth understanding of the psychological state of the students, there are questions to actively guide; The third is to encourage students, inform students to ensure the importance of positive psychology, encourage students at this time of psychology; The forth is to summarize the students, there is a problem to correct, no problem to encourage students to continue to maintain; The fifth is to expand the goal of understanding students, from behavioral psychology to motivational psychology, and so on, to stimulate students' own potential, guide students to set up correct concepts, and promote students to complete self-regulation and development.

\subsection{To Establish a Positive Learning Environment}

The influence of environment on students is particularly important. For students, the environmental construction of a school can influence the values of students. Schools with more positive energy can influence students and guide them to become positive and full of positive energy. Higher vocational schools, for example, can put positive publicity slogans, and energy in the university to carry out the positive energy of lectures, practical activity of positive energy, games, contests, etc., environment influence on students is subtle, is full of positive energy for a long time, can stimulate students' potential, to a great extent prompted students self regulating and self growth, realize self-worth.

The concept of positive psychology believes that when a person is in a negative and depressed state for a long time, it is easy to have schizophrenia. To prevent it from producing schizophrenia, it is necessary to fundamentally change students' thinking and concepts. Therefore, positive psychology believes that when facing psychological problems, one should not blindly escape, but should face the root of the problem directly, so as to improve the individual's psychological immunity and resist negative emotions in mental health. Therefore, mental health education needs to help students solve their own psychological problems, so as to pay close attention to the inner needs of students and cultivate their positive and optimistic mental state. In the previous studies, students in vocational colleges were not recognized by their parents and teachers due to their poor academic performance, and other advantages of their own existence were also downplayed. For teachers in vocational colleges, they need to be more More energy is devoted to cultivating students' personality, helping students improve their ability to resist negative emotions, and establishing students' positive outlook on life, guiding students to play to their own advantages and become useful to society and responsible for themselves. 
When improving, we need to strengthen the positive psychology of the students, do some investigations or experiments in the early stage to find out the potential advantages of the students, help the students to dig deeper into themselves, find their own shining points, and design questionnaires based on the different personalities of the students., To organize a personality analysis meeting to help students find their own strengths and teach them how to use their strengths to improve themselves. For example, some students test that they have leadership skills. Teachers can guide students to participate in class activities and provide them with more opportunities to display their leadership skills; some students will test that they have creative talents. Teachers can encourage students to Submission of newspapers and periodicals...Through these tests, students can understand their own strengths, make rational use of their strengths, find their own shining points, inspire their selfconfidence, and become a useful person.

\section{CONCLUSION}

In short, the positive psychology education, for students to study in higher vocational career has important role, in order to avoid when facing the employment academic pressure to students psychological problems, appropriate psychological counseling, can help students to complete the job, by putting a positive use of the teaching of education concept, establish a positive teaching environment, using the active teaching mode, achieve the goal of teaching actively.

Schools can carry out a variety of emotional experience activities, such as psychological team counseling activities, positive psychological training camps, and mental health lectures, so that more students can understand and integrate into various mental health education activities, so as to self-regulate and strengthen their inner self, To generate positive and upward power, increase its ability to resist negative emotions, and survive emotional crises.

\section{REFERENCES}

[1] CY. Li, Research on stress and emotion status analysis and coping strategies in mental health education of higher vocational students, in: J. Shanxi Youth,2021, pp.169-170.

[2] J. Shi, Study on the mental health status and countermeasures of higher vocational college students based on the diversification of students -Taking Nanjing city vocational college as an example, in: J. Heilongjiang Science, vol. 12, 201, pp.30-32.

[3] BL. Deng, SQ. Chen, Analysis of mental health status and countermeasures of students majoring in preschool education in higher vocational colleges, in: J. Journal of Hubei Open Vocational College, vol. 34, 201, pp. 60-62+65.

[4] JN. Zhai, YX. Qiu, Research on employment psychology of higher vocational students under positive psychology in: J. Employment and Security,2020, pp. 43-44.

[5] XQ. Liu, Investigation and analysis on students needs of mental health education course in higher vocational colleges, in: J. Theoretical Research and Practice of Innovation and Entrepreneurship, vol. 3, 2020, pp. 82-84.

[6] PX. Zhou, Improving the psychological quality of higher vocational students from the perspective of positive psychology, in: J. Business Culture,2020, pp. 19-21.

[7] SH. Wang, XT. Zhao, YY. Zhao, A study on the status quo and educational strategies of students' mental health in higher vocational colleges, in: J. Health Vocational Education, vol. 38, 2020, pp. 153155 . 